\title{
PENGARUH TERAPI NON FARMAKOLOGI DENGAN MEDIA MURROTAL AL-QUR'AN KOMBINASI SENAM DYSMENORRHEA TERHADAP PENURUNAN NYERI HAID DI PANTI ASUHAN SEJAHTERA AISYIYAH PANGKAJENE
}

\author{
Hamdiyah \\ Sekolah Tinggi Ilmu Kesehatan Muhammadiyah
}

\begin{abstract}
Background: Reproductive health is an important part of general health and main characteristic to increase the degree of human health from childhood, and most important is adolescence and adulthood. And determine the level of reproductive health for women dan men. This can affect future generations' health. Women who have entered puberty will who experienced menstruation, most of women will experience discomfort or painful periods and usually called by dysmenorrhea. Dysmenorrhea Management can used by pharmacological and non-pharmacological therapy that have been carried out as an effort to overcome dysmenorrhea such as analgesic drugs, hormonal therapy, non-steroidal prostaglandin drugs, and dilatation of the cervical canal.This therapy can Addiction and Negative Effects and drug side effects is dangerous for patient while non-pharmacological therapy common is relaxation therapy with listening to music, acupuncture, acupressure, sports, and spiritual therapy. One of non-pharmacological therapy is gymnastics / sports, and spiritual therapy that is usually by dzikir also listening the holy Quran recitation able to provide a relaxing effect because it can activate the relaxing effect because it can activate the hormone endorphin. Methods: The research is quasi eksperimental model with the pretest- posttest two group design. The sample of this research that adolence in Panti Asuhan Sejahtera Aisyiyah Pangkajene, Sidrap. Respondent recruitment by using purposive sampling. The data analysis used independent t-test.The research result from independent $t$-test. Result:The results showed there is a significant effect of non farmakologi therapy with murottal therapy (Al-Qur'an) combination dysmenorrhea gymnastics in reducing pain level. Conclusion: Of the analysis ( $P v=$ 0.000) $<\alpha(0.005)$ each month is the first month, the second month and the thirdh month.
\end{abstract}

Keywords: Dysmenorrhea, Murrotal, Dysmenorrhea Gymnastics

\section{PENDAHULUAN}

Kesehatan reproduksi merupakan bagian penting dari kesehatan umum dan ciri utama untuk meningkatkan derajat kesehatan manusia mulai dari masa kanak-kanak, dan paling penting pada masa remaja dan dewasa.Serta menentukan tingkat kesehatan reproduksi bagi perempuan dan laki-laki. Hal ini dapat mempengaruhi kesehatan generasi berikutnya (Ammar. 2016)

Seorang perempuan yang telah memasuki usia puberitas mengalami menstruasi. Menstruasi adalah 
pengeluaran cairan secara berkala dari vagina selama usia reproduksi. Gangguan ginekologi yang sering terjadi adalah gangguan yang berhubungan dengan siklus menstruasi adalah masalah yang hampir sebagian besar wanita mengalami rasa tidak nyaman atau nyeri yang hebat.Hal ini biasa disebut dengan nyeri haid(dismenore) (Zainuddin. 2014; Putri.2017).

Nyeri haid (Dysmenorrhea) adalah nyeri menjelang atau selama menstruasi yang dapat bersifat primer atau sekunder akibat adanya peningkatan hormon prostaglandin yang mengakibatkan otot uterus berkontraksi. Dysmenorrhea terbagi menjadi dua yaitu dismenore primer dan dismenore sekunder.

Menurut data World Health Organization (WHO) di Indonesia, angka kejadian dysmenorrhea sebanyak $55 \%$ dikalangan usia produktif, dan $15 \%$ diantaranya mengeluhkan aktivitas menjadi terbatas karena mengalami dismenore (Putri. 2017).

Penanganan dismenore dapat dilakukan dengan terapi farmakologi dan non-farmakologi yang telah dilakukan sebagai upaya mengatasi dismenore antara lain pemberian obat-obatan analgetik, terapi hormonal, obat nonsteroid prostaglandin, dan dilatasi kanalis servikalis. Terapi ini dapat berdampak ketagihan da memberikan efek samping obat yang berbahaya bagi pasien (Zainuddin. 2014). Sedangkan terapi non farmakologi yang biasa dilakukan adalah terapi relaksasi dengan mendengarkan musik, akupuntur, akupresure, olahraga, dan terapi spiritual (Sumaryani. 2015).

Salah satu terapi nonfarmakologi yaitu senam/olahraga, dan terapi spiritual yang biasa dilakukan adalah dengan berdzikir maupun mendengarkan lantunan ayat-ayat suci Al-Quran tersebut mampu memberikan efek relaksasi karena dapat mengaktifkan efek relaksasi karena dapat mengaktifkan hormon endorphin, meningkatkan perasan rileks, mengalihkan perhatian dari rasa takut, cemas dan tegang, memperbaiki sistem kimia tubuh sehingga menurunkan tekanan darah dan memperlambat pernapasan (Sumaryani. 2015; Nuraeni. 2017).

Terdapat beberapa pendapat mengatakan bahwa seorang wanita yang dalam keadaan hadas besar (misalnya dalam keadaan haid) membaca Al-Qur'an itu tidak boleh membaca membaca AlQur'an (Tim PP Muhammadiyah. 2003)

Berdasarkan observasi sederhana ditemukan salah satu anak di Panti Asuhan Sejahtera Aisyiyah Pangkajene mengatakan bahwa tidak boleh melakukan kegiatan islami termasuk membaca alquran, shalat, puasa jika dalam keadaan haid.Observasi sederhana juga dilakukan dimasyarakat berpedapat yang sama tentang larangan tersebut namun beberapa orang tidak mengetahui lebih dalam bahwa membaca dzikir, takbir, tasbih dan bismillah ketika hendak makan atau pekerjaan lainnya, membaca fiqih, hadists, doa-doa serta mendengarkan al-quran tidak diharamkan bagi wanita haid. Sedangkan membaca al-Qur'an bagi wanita haid itu sendiri dengan mata atau hati tanpa diucapkan dengan lisan maka tidak apa-apa hukumnya sedangkan jika membaca dengan lisan maka banyak ulama mengharamkannya dan tidak memperbolehkannya (Syaikh Muhammad Bin Shaleh Al-Utsaimin)

Dari hasil penelitian yang dilakukan oleh Rilla dkk mendapatkan hasil bahwa Terapi musik dan terapi murrotal memiliki efek terhadap efek terapi musik dan terapi murrotal memiliki efek 
terhadap penurunan tingkat nyeri tetapi tidak memiliki efek yang signifikan terhadap kestabilan tanda-tanda vital pada pasien pasca bedah. Terapi murrotal memiliki efektivitas lebih baik dibandingkan terapi musik terhadap penurunan tingkat nyeri tetapi tidak memiliki efek terhadap kestabilan tandatanda vital pasien pascabedah (Rilla,Ropi, Sriati. 2014).

Berdasarkan data dari berbagai negara, angka kejadian dysmenorrhea didunia cukup tinggi, diperikrakan sekitar $50 \%$ dari seluruh wanita yang mengalami dismenore dalam siklus menstruasi, data dari Panti Asuhan Sejahtera Aisyiyah diperkirakan hampir 95\% wanita disana mengalami dismenore berat setiap bulannya yang menyebabkan mereka tidak mampu melakukan kegiatan sehari - hari dan sering tidak hadir sekolah dengan alasan tidak dapat berkonstarsi dalam belajar karena rasa nyeri yang mereka rasakan begitu hebat. Keadaan tersebut menyebabkan menurunkannya kualitas hidup wanita.Masalah ini biasanya tidak terdiagnosa dan tidak tidak diberikan perawatan.

Berdasarkan uraian latar belakang permasalahan diatas mendorong penulis untuk melakukan penelitian dengan judul "Pengaruh Terapi Non Farmakologi dengan Media Al-Qur'an Kombinasi Senam Dysmenorrhea terhadap Penurunan Nyeri Haid di Panti Asuhan Sejahtera Aisyiyah Pangkajene".

\section{METODE PENELITIAN}

Tehnik pengumpulan data dengan menggunakan 2 kuesioner yaitu yang pertama kuesioner Skala pendeskripsi verbal (VDS/Verbal Deskriptor Scale dan kuesioner kedua dengan kualitas nyeri.

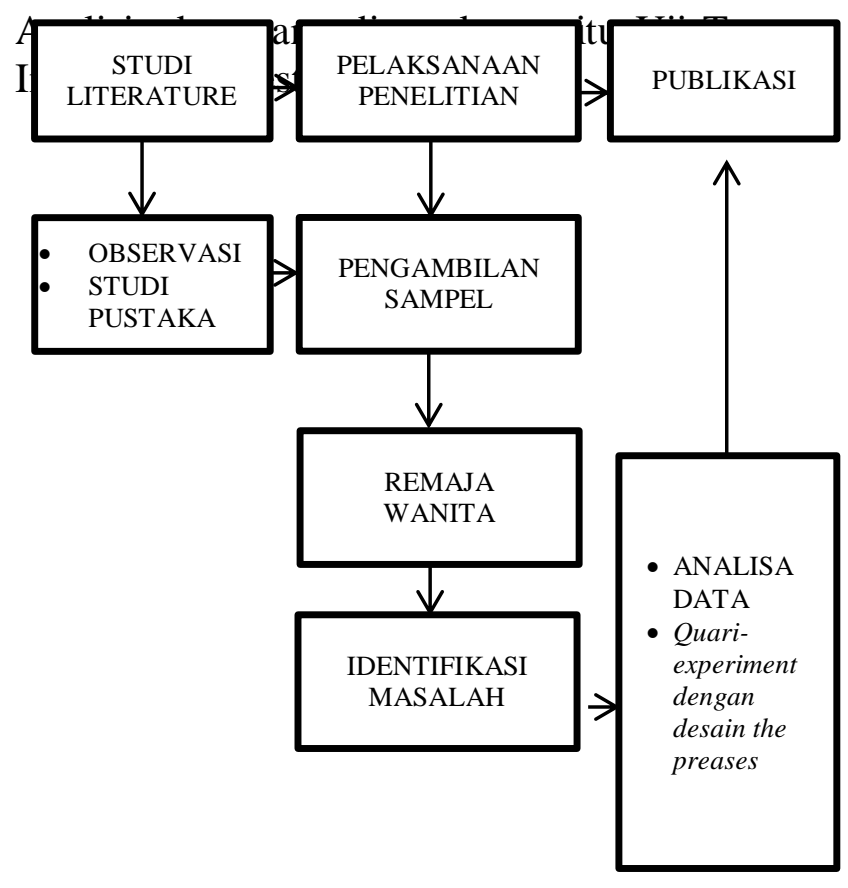

HASIL PENELITIAN

1. Analisis Univariat

Tabel 1. Distribusi Frekuensi

Karteristik Responden

\begin{tabular}{|c|c|c|c|c|}
\hline \multirow[t]{2}{*}{ IMT } & \multicolumn{2}{|c|}{ Kasus } & \multicolumn{2}{|c|}{ Kontrol } \\
\hline & $\mathrm{n}$ & $\%$ & $\mathrm{n}$ & $\%$ \\
\hline Kurus & 1 & 6.7 & 2 & 13.3 \\
\hline Normal & 14 & 93.7 & 12 & 80 \\
\hline Gemuk & 0 & 0 & 1 & 6.7 \\
\hline Total & 15 & 100 & 15 & 100 \\
\hline \multirow{2}{*}{ Umur } & \multicolumn{2}{|c|}{ Kasus } & \multicolumn{2}{|c|}{ Kontrol } \\
\hline & $\mathrm{n}$ & $\%$ & $\mathrm{n}$ & $\%$ \\
\hline $\begin{array}{l}\text { Remaja Awal } \\
(12-15 \mathrm{Th})\end{array}$ & 6 & 40 & 2 & 13.3 \\
\hline \multicolumn{5}{|l|}{ Remaja } \\
\hline $\begin{array}{l}\text { Tengah } \\
(>15-18 \mathrm{Th})\end{array}$ & 5 & 33.3 & 8 & 54.4 \\
\hline $\begin{array}{l}\text { Remaja Akhir } \\
(>18-21 \mathrm{Th})\end{array}$ & 4 & 26.7 & 5 & 33.3 \\
\hline Total & 15 & 100 & 15 & 100 \\
\hline \multirow{2}{*}{ Pendidikan } & \multicolumn{2}{|c|}{ Kasus } & \multicolumn{2}{|c|}{ Kontrol } \\
\hline & $\mathrm{n}$ & $\%$ & $\mathrm{n}$ & $\%$ \\
\hline SD & 1 & 6.6 & 0 & 0 \\
\hline SMP & 7 & 46.7 & 4 & 26.7 \\
\hline SMA & 7 & 46.7 & 11 & 73.3 \\
\hline Total & 15 & 100 & 15 & 100 \\
\hline
\end{tabular}


Sumber: Data Primer 2019

\section{Analisis Bivariat}

Tabel 2. Distribusi Remaja Putri Pada Kelompok Kasus Dengan Intervensi Mendengarkan Murrotal Al-Qur'an dan senam dismenorhea Terhadap Penurunan Nyeri Haid di Panti Asuhan Sejahtera Aisyiyah Pangkajene Tahun 2019

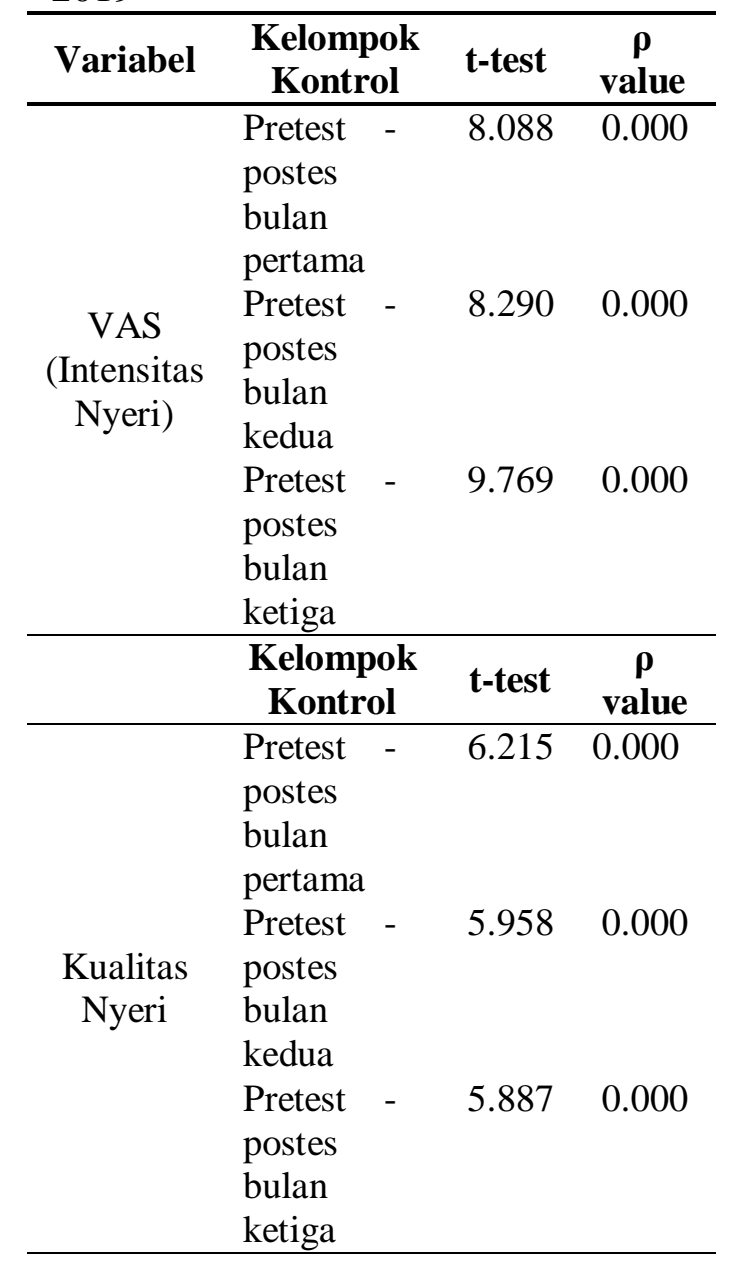

\section{PEMBAHASAN}

Berdasarkan hasil analisa data pada tabel 1, dari 30 responden yang terdiri dari 15 responden kelompok intervensi dan 15 responden kelompok kontrol, berdasarkan variabel 1 IMT (Indeks Massa Tubuh)dapat diinterprestasikan bahwa jumlah sampel kelompok intervensi sebanyak 15 Responden dengan IMT kategori normal sebanyak 14 (93.7\%) dan IMT kategori kurus sebanyak 1 (6.7\%). Pada kelompok kontrol jumlah sampel sebanyak 15 Responden dengan IMT kategori normal sebanyak 12 (80\%), IMT kategori kurus sebanyak $2(13.3 \%)$. dan IMT kategori gemuk sebanyak 1 (6.7\%).

Terapi non farmakologik dengan media murrotal Al-qur'an kombinasi senam dismenore diharapkan dapat mengurangi nyeri haid yang dirasakan remaja putri. Diketahui pengertian Dismenore adalah nyeri saat menstruasi yang timbul menjelang atau selama menstruasi, membuat wanita tersebut terganggu aktifitasnya dengan begitu juga dapat mengganggu proses belajar remaja putri.sebagaimana hail penelitian yang dilakukan Salsabila dkk (2017) menunjukkan bahwa terdapat hubungan yang signifikan antara nyeri (dismenore) dengan aktivitas belajar.

Berdasarkan dari variabel umur dapat diketahui bahwa remaja putri pada kelompok intervensi sebanyak 6 (40\%) pada remaja awal (berusia 12-15 th), 5 $(33.3 \%)$ pada remaja tengah (berusia $>15$ 18 th), dan $4(26.7 \%)$ pada remaja akhir (berusia >18-21 th). Sedangkan remaja putri pada kelompok control sebagian besar remaja tengah sebanyak 8 (54.4\%), remaja akhir sebanyak $5(33.3 \%)$ dan remaja awala $2(13.3 \%)$.

Berdasarkan dari variabel pendidikan diketahui remaja putri yang pendidikan SMP, SMA sebanyak 7 (46.7\%), dan SD sebanyak 1 (6.6\%) pada kelompok intervensi, sedangkan pada kelompok kontrol sebagian besar pendidikan SMA sebanyak 11 (73.3\%), dan SMP sebanyak 4 (26.7\%). 
Berdasarkan tabel 2 dapat diinterprestasikan bahwa hasil analisis paired $t$ test pada bulan pertama menunjukan $p$ value $0.000(p<0.05)$ dan nilai $\mathrm{t}$ hitung (8.088) $>\mathrm{t}$ tabel adalah 1,812 sehingga dapat disimpulkan $\mathrm{H}_{0}$ ditolak dan $\mathrm{H}_{\mathrm{a}}$ diterima artinya bahwa terdapat pengaruh terapi non farmakologik dengan media murrotal Al-qur'an kombinasi senam dismenore terhadap penurunan nyeri haid.

Pada bulan kedua menunjukan bahwa $p$ value $0.000(p<0.05)$ dan nilai $\mathrm{t}$ hitung (8.290) > t tabel adalah 1,812 sehingga dapat disimpulkan $\mathrm{H}_{0}$ ditolak dan $\mathrm{H}_{\mathrm{a}}$ diterima artinya terdapat pengaruh terapi non farmakologik dengan media murrotal Al-qur'an kombinasi senam dismenore terhadap penurunan nyeri haid.

Sedangkan pada bulan ketiga menunjukan bahwa $p$ value 0.000 $(p<0.05)$ dan nilai $\mathrm{t}$ hitung $(9.769)>\mathrm{t}$ tabel adalah 1,812 sehingga dapat disimpulkan $\mathrm{H}_{0}$ ditolak dan $\mathrm{H}_{\mathrm{a}}$ diterima artinya terdapat pengaruh terapi non farmakologik dengan media murrotal Alqur'an kombinasi senam dysmenorrhea terhadap penurunan nyeri haid.

\section{KESIMPULAN DAN SARAN}

Kesimpulan

Adapun kesimpulan dalam penelitian ini yaitu memperoleh hasil bahwa pada bulan pertama $(0.000<0.05)$, pada bulan kedua menunjukkan $\mathrm{p}$ value $0.000<0.05)$, dan pada bulan ketiga menunjukkan $0.000<0.05$ ) sehingga dapat disimpulkan bahwa terdapat pengaruh terapi non farmakologi dengan media murrotal Al-Qur'an kombinasi senam dysmenorrhea terhadap penurunan nyeri haid.

Saran
1. Untuk tempat penelitian diharapkan untuk melanjutkan terapi non farmakologi dengan media murrotal Al-Qur'an kombinasi dengan senam dysmenorrhea.

2. Untuk penelitian selanjutnya, diharapkan dapat menambahkan jumlah variabel, mengkhususkan untuk memberikan intervensi kepada yang mengalami nyeri dengan derajat nyeri tingkat $>5$.

\section{DAFTAR RUJUKAN}

Ammar U.R. 2016. Faktor Resiko Dysmenorrhea Primer Pada Wanita Usia Subur di Kelurahan Ploso Kecamatan Tambaksari Surabaya. Journal Berkala Epidemiologi. Vol. 4 No.37-49. https://media.neliti.com/media/pu blications/74834-ID-none.pdf

Nuraeni. 2017. Pengaruh Senam Dismenore Terhadap Penurunan Nyeri Pada Remaja Putri SMK 1 Tapango Kecamatan Tapango Kabupaten Polewali Mandar. STIKES Bina Generasi Polewali. Jurnal Ilmu Bidan, Vol II No.1. https://media.neliti.com/media/pu blications/227218-pengaruhsenam-dismenore-terhadappenuru-7a8f8d0a.pdf

Putri, A.S. 2017. Hubungan Antara Nyeri Haid (Dismenore) Terhadap Aktivitas Belajar Pada Siswi Kelas XI SMA Negeri 52 Jakarta. Program Ilmu Kesehatan Masyarakat, Fakultas Ilmu Keolahragaan, Universitas Negeri Malang.http://journal.um.ac.id/in dex.php/preventia/article/downlo ad/10013/4756

Putri, S.A, 2017. Hubungan Antara Nyeri Haid (dismenore) Terhadap 
Aktivitas Belajar pada Siswi Kelas XI SMA Negeri 52 Jakarta. Universitas Negeri Malang.http://journal.um.ac.id/in dex.php/preventia/article/downlo ad/10013/4756

Rilla E.V., Ropi H., Sriati A. 2014. Terapi Murrotal Efektifitas Menurunkan Tingkat Nyeri Dibanding Terapi Musik Pada Pasien Pascabedah. Junal keperawatan Indonesia, Volume 17, No.2, Juli 2014, Hal 78-80 pISSN 1410-4490, eISSN 23549203,https://media.neliti.co $\mathrm{m} / \mathrm{media}$ /publications/105189-ID -terapi- murottal - efektifmenurunkan-tingk.pdf

Sumaryani S., Sari P.I. 2015. Senam dysmenorrhea berbasis $\mathrm{Ar}$ Rahman terhadap penurunan Nyeri. Jurnal Ners Vol. 10 No. 2 : 360-365. https://media.neliti.com/media/pu blications/117825-ID-none.pdf

Syaikh Muhammad Bin Shaleh Al'Utsaimin diterjemahkan oleh Muhammad Yusuf Harun. Darah KebiasaanWanita.http://kediri.mu hammadiyah.or.id/muhfile/kediri/ download/Hukum\%20Darah\%20 Kebiasaan\%20Wanita. pdf

Tim PP Muhammadiyah Majilis Tarjih. 2015. Fatwa-fatwa Tarjih: Tanya jawab Agama 2. Cetakan ketujuh.

Zainuddin A.J.2014. Pengaruh terapi music religi terhadap penurunan derajat nyeri menstruasi pada siswi MAN 2 Model Makassar.Jurusan Keperawatan Fakultas Ilmu Kesehatan Universitas Islam Negeri Alauddin Makassar. http://repositori.uinalauddin.ac.i
d/6589/1/Andi\%20Jumriati\%20Z

ainuddin_opt.pdf 